2. Blank PR, Schwenkglenks M, Szucs TD. Influenza vaccination coverage rates in five European countries during season 2006/07 and trends over six consecutive seasons. BMC Public Health 2008;8:272. http://dx. doi.org/10.1186/1471-2458-8-272

3. Brien S, Kwong JC, Buckeridge DL. The determinants of 2009 pandemic A/H1N1 influenza vaccination: a systematic review. Vaccine 2012;30:1255-64. http://dx.doi.org/10.1016/j.vaccine.2011.12.089

4. Van Rossem I, Vandevoorde J, Buyl R, Deridder S, Devroey D. Notification about influenza vaccination in Belgium: a descriptive study of how people want to be informed. Prim Care Respir J 2012;21:308-12. http://dx.doi.org/10.4104/ pcrj.2012.000

5. Kroneman M, van Essen GA, Paget WJ. Influenza vaccination coverage and reasons to refrain among high-risk persons in four European countries. Vaccine 2006; 24:622-8. http://dx.doi.org/10.1016/j.vaccine.2005.08.040

6. Evans MR, Watson PA. Why do older people not get immunised against influenza?
A community survey. Vaccine 2003;21(19-20):2421-7. http://dx.doi.org/10.1016/ S0264-410X(03)00059-8

7. Rubin GJ, Potts HWW, Michie S. Likely uptake of swine and seasonal flu vaccines among healthcare workers. A cross-sectional analysis of UK telephone survey data. Vaccine 2011;29:2421-8. http://dx.doi.org/10.1016/j.vaccine.2011.01.035

8. Skurnik I, Yoon C, Schwarz N. "Myths \& Facts" about the flu: Health education campaigns can reduce vaccination intentions. 2007. h ttp://www. granthalliburton.org/images/Skurnik.pdf

9. Lewis-Parmar H, McCann R. Achieving national influenza vaccine targets - an investigation of the factors affecting influenza vaccine uptake in older persons and people with diabetes. Commun Dis Public Health 2002;5:119-26.

10. O'Reilly FW, Cran GW, Stevens AB. Factors affecting influenza vaccine uptake among health care workers. Occup Med 2005;55:474-9.

http://dx.doi.org/10.1093/ occmed/kqi099

\title{
Understanding the true burden of COPD: the epidemiological challenges
}

See linked article by McKay et al. on pg 313

\section{*Sundeep S Salvi ${ }^{\mathrm{a}}$, Roslina Manap ${ }^{\mathrm{b}}$, Richard Beasley}

a Chest Research Foundation, Pune, India,

b Universiti Kebangsaan Malaysia Medical Centre, Kuala Lumpur, Malaysia,

Medical Research Institute of New Zealand, Wellington, New Zealand

*Correspondence: Dr Sundeep S Salvi, Director, Chest Research Foundation, Marigold Complex, Kalyaninagar, Pune 411014, India Tel: +919921211000 Fax: +912027035371

E-mail: ssalvi@crfindia.com

According to the World Health Organization (WHO), an estimated 3 million people die due to chronic obstructive pulmonary disease (COPD) every year, making it the fourth leading cause of death in the world. ${ }^{1}$ Around $90 \%$ of these deaths occur in low- and middleincome countries, with India and China alone estimated to account for $66 \%$ of total global COPD mortality. ${ }^{2}$ By 2020 , it is anticipated that COPD will become the third leading cause of death in the world. ${ }^{1}$ The largest number of deaths will be in the South East Asian region, where mortality due to COPD is expected to grow by $160 \%$, totalling more than the combined numbers of deaths due to malaria, tuberculosis and HIV/AIDS.

However, these data may well underestimate the problem. Tan et al. ${ }^{4}$ estimated COPD prevalence in the Asia Pacific region to be $6.3 \%$, compared to the rate of $3.9 \%$ extrapolated from $\mathrm{WHO}$ data. Similarly, COPD prevalence in China was found to be 2.5 times greater $^{5}$ than that estimated by WHO. Despite this apparently huge burden, there are few good quality epidemiological studies on COPD prevalence in South East Asia. For several decades the major health burden has been communicable diseases such as tuberculosis, malaria and HIVIAIDS; governments, lay people and physicians have been slow to recognise the impact of COPD. Yet with the increasing morbidity and mortality from COPD - which has already overtaken most communicable diseases as a leading cause of death - there is now a need for more intensive research and analysis of the epidemiology of COPD in this region.

In this issue of the $P C R J$, McKay and colleagues report a systematic review on the prevalence of COPD in India. ${ }^{6}$ India is one of the largest countries in Asia with an estimated population of over 1.2 billion, where small increases in the percentage prevalence of a disease can translate into large increases in the number of cases. This huge population is exposed to a large number of COPD risk factors. Tobacco smoking rates in India vary from $13.3 \%$ to $59.5 \%$ amongst men and $0.2 \%$ to $22 \%$ amongst women. ${ }^{7}$ Around $70 \%$ of smokers in India smoke 'bidis' instead of cigarettes, which contain crude tobacco (0.15-0.25g) loosely packed in hand-rolled dried leaves of tendu (Diisopyros melanoxylon). The smoke from bidis contains 5 times more tar than the smoke from cigarettes, making bidi smoking a far greater risk factor for COPD than cigarette smoking. ${ }^{8}$ But more importantly, over $70 \%$ of homes in India use biomass fuel for cooking and heating, which again poses a greater risk factor for COPD than tobacco smoking. ${ }^{9}$ The prevalence of other risk factors such as early childhood lower respiratory tract infections, post-pulmonary tuberculosis, chronic poorly controlled asthma, poor socioeconomic status and a growing ageing population is also very high.

McKay et al. reviewed a total of 16 papers on COPD prevalence published from 1980 onwards. Disappointingly, they could not identify a single study that provided a rigorous estimate of COPD prevalence using a relatively standard spirometry-based definition, and were therefore unable to perform a meta-analysis. ${ }^{6}$ Five of the 16 studies examined the prevalence of chronic bronchitis as a surrogate for COPD using validated questionnaires, while the remaining studies defined COPD using less traditional and non-standard methods. The results of this study beg some important questions:

- What are the standard research tools and methodology needed to define COPD in population studies?

- And why has a country like India not been able to conduct such a study?

Unlike asthma (a term coined by Hippocrates over 3000 years ago), COPD is a relatively new disease that has undergone remarkable changes in its terminology over the last 350 years. In the early 1800s, the terms 'bronchitis' (introduced by the British physician Charles Badham) and 'emphysema' (introduced by the Frenchman Laennec) were proposed. For the next 100 years 'emphysema' was used largely by American physicians, and 'chronic bronchitis' by the British, and in 
later years this confusion was compounded by the use of additional terms such as chronic airflow limitation (CAL) and chronic obstructive airways disease (COAD). In 1965, Briscoe argued that this confusion should end, and the term 'chronic obstructive pulmonary disease' or 'COPD' was formally approved. ${ }^{10}$

The next major challenge was to define COPD, a process which evolved slowly compared to the rapid advances that took place in our understanding of the disease pathogenesis and its clinical characteristics." Most definitions included the presence of (largely non-specific) respiratory symptoms and histopathological changes, neither of which were useful for epidemiologists carrying out COPD population studies. For many years the respiratory health questionnaire designed by the British Thoracic Society ("presence of productive cough lasting for more than 3 months during 2 consecutive years") remained the main epidemiological tool to define the prevalence of chronic bronchitis as a surrogate for COPD in population studies. It was soon realised that this tool was neither sensitive nor specific for diagnosing COPD.

After the success of the Global Initiative for Asthma (GINA), the Global Initiative for Obstructive Lung Disease (GOLD) was launched in 1997. Its primary objectives were to streamline the definition of COPD and offer guidelines on diagnosis and management to physicians worldwide. The first GOLD consensus report was published four years later. ${ }^{12}$ For the first time, spirometry was recommended as the gold standard diagnostic test for COPD, though there was an additional category of patients (called GOLD stage 0 ) that had respiratory symptoms commensurate with COPD despite having normal spirometry. But in 2006, the GOLD committee excluded this category. Presence of airflow limitation was now the sole defining criteria for COPD.

The Burden of Obstructive Lung Disease (BOLD) was formed in 2002 to set quality standards for defining COPD in epidemiological studies. ${ }^{13}$ The BOLD Committee recommended the use of a respiratory questionnaire and good quality spirometry to determine the presence of COPD. Consistent with the GOLD guidelines, it recommended using a post-bronchodilator $\mathrm{FEV}_{1} / \mathrm{FVC}$ ratio of $<0.7$ to diagnose COPD. Until the GOLD guidelines were introduced, spirometry was rarely used to study the prevalence of COPD - and even when it was, many studies lacked quality assurance measures and used only prebronchodilator values; a significant number of asthma patients were therefore falsely labelled as having COPD. Spirometry has remained a poorly used diagnostic tool in most countries across the world. In India, up to $70 \%$ of patients with COPD have never had a spirometry test (personal observation). The need for post-bronchodilator spirometry in epidemiological studies requires training of field workers, not only to perform spirometry according to ATS/ERS quality standards but also to administer short-acting bronchodilators via inhalers. Despite all these challenges, the BOLD study has now been conducted in 21 countries across the world. This has not only helped us understand the burden of COPD using standardised, validated tools, but has also given us an opportunity to compare prevalence rates between different countries.

However, new challenges have emerged. BOLD defined COPD as a post-bronchodilator $\mathrm{FEV}_{1} / \mathrm{FVC}$ ratio of $<0.7$, in accordance with GOLD, as well as the American and European Respiratory Societies, ${ }^{14}$ Canadian Thoracic Society ${ }^{15}$ and the British NICE guidelines. ${ }^{16}$ But the fixed $F E V_{1} / F V C$ ratio of $<0.7$ has been criticised because it underdiagnoses COPD in younger shorter patients and over-diagnoses
COPD in older taller patients. ${ }^{17,18}$ To overcome these issues, use of the lower limit of normal (LLN) FEV $1 / F V C$ ratio (i.e. subjects below the 5 th percentile of the predicted $\mathrm{FEV}_{1} / \mathrm{FVC}$ value for their race, gender, age and height) was recommended by the ATS and ERS in 2005 as the defining criterion for COPD. ${ }^{19}$ Another major limitation is that a postbronchodilator $\mathrm{FEV}_{1} / \mathrm{FVC}$ ratio $<0.7$ may occur in other respiratory disorders such as long-standing asthma and bronchiectasis. This has led to the recommendation that spirometry be used with caution for disease diagnosis, and that the term 'COPD' should only be used in the appropriate clinical (diagnostic) context. ${ }^{20}$ This issue is particularly important in epidemiological studies in developing countries, where undiagnosed or poorly treated asthma and bronchiectasis secondary to tuberculosis and other respiratory infections may be more prevalent.

Over the last seven years, debate has continued on which COPD diagnostic criterion is the best - the post-bronchodilator fixed $\mathrm{FEV}_{1} / \mathrm{FVC}$ ratio $<0.7$, or the LLN FEV $1 / F V C$ ratio. BOLD, ATS and ERS have subsequently revised their guidelines to use the LLN criterion. Yet recent evidence suggests that the LLN criterion not only underestimates COPD, ${ }^{21}$ but also excludes a substantial population with important clinical manifestations and a high consumption of health care resources. ${ }^{22,23}$ And if the LLN criterion has to be used, should it be pre-bronchodilator or post-bronchodilator? Prebronchodilator LLN values overestimate COPD prevalence by $31 \%$ compared to post-bronchodilator LLN values. ${ }^{24}$ The ERS Task Force has recently recommended using post-bronchodilator $L L N$ values to define COPD. ${ }^{25}$ In addition, the LLN criterion depends on reliable reference values derived from the healthy local population; many countries don't have their own reference values for spirometry, and even if they do, they are in all likelihood based on values obtained from asymptomatic never-smokers. In populations such as the Asia Pacific region, where smoking is not the overwhelming cause of COPD, the 'apparently healthy population' may include many who suffer from asymptomatic undiagnosed airflow limitation due to factors other than tobacco smoking, which may lead to significant underdiagnosis of true COPD in these population studies.

Since many countries lack reliable locally-generated predicted values for spirometry, and given the other issues associated with the LLN criterion, the GOLD guidelines have continued to define COPD using the fixed post-bronchodilator $\mathrm{FEV}_{1} / \mathrm{FVC}$ ratio $<0.7$, whilst acknowledging the fact that it underdiagnoses and over-diagnoses at extremes of adult age. As Mannino comments: "Splitting hairs over the most precise definition of COPD while many people with disease are undiagnosed and untreated because primary care providers are confused by the multiplicity of these definitions, is a disservice to patients and the medical community..." ${ }^{26}$ Whether we use the fixed ratio or the LLN, each has its own drawbacks and limitations. However, the major concern is that the difference in prevalence rates of COPD between these two criteria may be as high as 200\%. . $4.27^{27}$ Irrespective of which criterion is used in the future, we still have to accept that we are only diagnosing fairly advanced COPD. Early or mild COPD, which primarily starts as a disease of the small airways, cannot be diagnosed either by the fixed ratio or the LLN criteria. We will therefore be missing a substantial number of patients who might otherwise benefit from early diagnosis, early preventative strategies and even early therapeutic interventions.

There are many challenges in determining the true prevalence of COPD in population studies. To summarise, these include: 
- A lack of awareness about COPD amongst healthcare policy makers, clinicians, medical researchers and lay people. There is a real need to conduct high quality COPD prevalence studies

- COPD is a relatively new term for an old disease that has evolved after an identity crisis. There is still a grey area about what 'COPD' actually means.

- Performing post-bronchodilator spirometry requires specialised training and a good quality assurance programme. There are logistical challenges if prevalence studies have to be conducted in remote areas that are not easily accessible

- There is poor consensus regarding which spirometric criterion (fixed ratio or LLN) should be used to define COPD. Both have their drawbacks, and produce prevalence rates that may differ by up to 2-fold

- The current spirometric criteria are poorly specific for COPD and will identify individuals with other respiratory disorders such as chronic asthma and bronchiectasis

- Both currently used spirometric diagnostic criteria do not diagnose early or mild COPD.

What about the future? Unless reliable epidemiological data is generated from countries across the world, especially from the South East Asian region, health policy makers will not be able to take appropriate decisions regarding effective preventative and management strategies for COPD. In order to generate this information, countries like India will have to follow currently accepted (albeit imperfect) diagnostic guidelines. The BOLD protocol is currently the most acceptable methodology to define COPD prevalence in different countries, and this is currently being studied in four cities across India. In the meantime, clinicians, epidemiologists and researchers must strive to work towards a definition of COPD that should be unambiguous, unbiased and reproducible in different settings. It should also be simple to use, capable of identifying most if not all patients likely to suffer from the disease, and be able to exclude other respiratory conditions with airflow obstruction. It is only then that we will understand the true burden of COPD, which will help drive appropriate policy decisions at local, national and global levels to reduce the morbidity and mortality that COPD currently poses to mankind.

Conflicts of interest The authors declare that they have no conflicts of interest in relation to this article.

Commissioned article; not externally peer-reviewed; accepted 8th August 2012; online 10th August 2012

(c) 2012 Primary Care Respiratory Society UK. All rights reserved http://dx.doi.org/10.4104/pcrj.2012.00082

Prim Care Respir J 2012; 21(3): 249-51

\section{References}

1. Murray CL, Lopez AD. Alternative projections of mortality, disability by cause 19902020. Global Burden of Disease Study. Lancet 1997;349:1498-504. http://dx.doi.org/10.1016/S0140-6736(96)07492-2

2. Lopez AD, Shibuya K, Rao C, et al. Chronic obstructive pulmonary disease: current burden and future projections. Eur Respir J 2006;27(2):397-412. http://dx.doi.org/10.1183/09031936.06.00025805

3. The Global Burden of Disease 2008. WHO. http://www.who.int/healthinfo/ global_burden_disease/projections/en/. Accessed on 8th August 2012.

4. Tan WC, Ng TP. COPD in Asia: Where East meets West. Chest 2008;133(2):517-27. http://dx.doi.org/10.1378/chest.07-1131

5. Chan-Yeung M, Ait-Khalet N, White N, Ip MS, Tan WC. The burden and impact of COPD in Asia and Africa. Int J Tuber Lung Dis 2004;8(1):2-14.
6. McKay A, Mahesh PA, Fordham JZ, Majeed A. Prevalence of COPD in India: A systematic review. Prim Care Respir J 2012;21:313-21. http://dx.doi.org/ 10.4104/pcrj.2012.00055

7. Chhabra SK, Rajpal S, Gupta R. Patterns of smoking in Delhi and comparison of chronic respiratory morbisity among beedi and cigarette smokers. Indian J Chest Dis Allied Sci 2001;43:19-26.

8. Salvi S, Agrawal A. India needs a national COPD prevention and control program. J Asso Phys India (Suppl) 2012;60:5-7.

9. Salvi S, Barnes PJ. Is exposure to biomass smoke the biggest risk factor for COPD globally? Chest 2010;138(1):3-6.

10. Petty TL. The history of COPD. Int J Chronic Obst Pulm Dis 2006;1(1):3-14. http://dx.doi.org/10.2147/copd.2006.1.1.3

11. Beasley R, Weatherall M, Travers J, Shirtcliffe P. Time to define the disorders of the syndrome of COPD. Lancet 2009;374(9691):670-2. http://dx.doi.org/10.1016/ S0140-6736(09)61541-5

12. NHLBIMHO WORKSHOP REPORT Global Initiative for Chronic Obstructive Pulmonary Disease (GOLD). Global strategy for the diagnosis, management and prevention of chronic obstructive pulmonary disease. Bethesda, MD, National Institutes of Health National Heart, Lung and Blood Institute: April 2001.

13. Buist AS, Vollmer WM, Sullivan SD, et al. The Burden of Obstructive Lung Disease Initiative (BOLD): rationale and design. COPD 2005;2(2):277-83. http://dx.doi.org/10.1081/COPD-57610

14. Celli BR, MacNee W, ATS/ERS Task Force. Standards for the diagnosis and treatment of patients with COPD: A summary of the ATS/ERS position paper. Eur Respir J 2004; 23(6):932-46. http://dx.doi.org/10.1183/09031936.04.00014304

15. O'Donnell DE, Hernandez P, Kaplan A, et al. Canadian Thoracic Society recommendations for management of chronic obstructive pulmonary disease - 2008 update - highlights for primary care. Can Respir J 2008;15 Suppl A:1A-8A.

16. O'Reilly J, Jones MM, Parnham J, Lovibond K, Rudolf M; Guideline Development Group. Management of stable chronic obstructive pulmonary disease in primary and secondary care: summary of updated NICE guidance. BMJ 2010;340:c3134. http://dx.doi.org/10.1136/bmj.c3134

17. Hansen JE, Sun XG, Wasserman K. Spirometric criteria for airway obstruction: Use percentage of FEV1/FVC ratio below the fifth percentile, not less than $70 \%$. Chest 2007;131(2):349-55. http://dx.doi.org/10.1378/chest.06-1349

18. Roberts SD, Farber MO, Knox KS, et al. FEV1/FVC ratio of $70 \%$ misclassifies patients with obstruction at the extremes of age. Chest 2006;130(1):200-06. http://dx.doi.org/10.1378/chest.130.1.200

19. Pellegrino R, Viegi $G$, Brusasco $V$, et al. Interpretative strategies for lung function tests. Eur Respir J 2005;26(5):948-68. http://dx.doi.org/10.1183/09031936.05.00035205

20. Postma DS, Brusselle G, Bush A, Holloway JW. I have taken my umbrella, so of course it does not rain. Thorax 2012;67(1):88-9. http://dx.doi.org/10.1136/thoraxjnl-2011-200758

21. Mohamed Hoesein FA, Zanen P, Lammers JW. Lower limit of normal or FEV1/FVC < 0.70 in diagnosing COPD: an evidence-based review. Respir Med 2011;105(6):90715. http://dx.doi.org/10.1016/j.rmed.2011.01.008

22. Alonso KLI, Ramos PDL, Glez-Moro JMR, CONSISTE Study Group. The use of the lower limit of normal as a criterion for COPD excludes patients with increased morbidity and high consumption of health care resources. Arch Bronconeumo/ 2012; 48(7):223-8. http://dx.doi.org/10.1016/j.arbr.2012.05.002

23. Mannino DM, Watt $G$, Hole $D$, et al. The natural history of chronic obstructive pulmonary disease. Eur Respir J 2006;27(3):627-43 http://dx.doi.org/ 10.1183/09031936.06.00024605

24. Shirtcliffe $P$, Weatherall $M$, Marsh $S$, et al. COPD prevalence in a random population survey: a matter of definition. Eur Respir J 2007;30(2):232-9. http://dx.doi.org/ 10.1183/09031936.00157906

25. Bakke PS, Rönmark E, Eagan T, et al. European Respiratory Society Task Force. Recommendations for epidemiological studies on COPD. Eur Respir J 2011;38(6): 1261-77. http://dx.doi.org/10.1183/09031936.00193809

26. Mannino DM. Defining chronic obstructive pulmonary disease... and the elephant in the room. Eur Respir J 2007;30(2):189-90. http://dx.doi.org/10.1183/09031936.00058707

27. Celli BR, Halbert RJ, Isonaka S, Schau B. Population impact of different definitions of airway obstruction. Eur Respir J 2003;22(2):268-73. http://dx.doi.org/10.1183/09031936.03.00075102 